\title{
BMJ Open The child's perspective on discomfort during medical research procedures: a descriptive study
}

\author{
Mira S Staphorst, ${ }^{1,2}$ Marc A Benninga, ${ }^{2}$ Margriet Bisschoff, ${ }^{3}$ Irma Bon, ${ }^{4}$ \\ Jan J V Busschbach, ${ }^{1}$ Kay Diederen, ${ }^{2}$ Johannes B van Goudoever, ${ }^{2,4}$ \\ Eric G Haarman, ${ }^{4}$ Joke A M Hunfeld, ${ }^{1}$ Vincent V W Jaddoe, ${ }^{3}$ Karin J M de Jong, ${ }^{5}$ \\ Johan $\mathrm{C}$ de Jongste, ${ }^{3}$ Angelika Kindermann, ${ }^{2}$ Marsh Königs, ${ }^{6}$ Jaap Oosterlaan, ${ }^{6}$ \\ Jan Passchier, ${ }^{7}$ Mariëlle W Pijnenburg, ${ }^{3}$ Liesbeth Reneman, ${ }^{2}$ Lissy de Ridder, ${ }^{3}$ \\ Hyke G Tamminga, ${ }^{2}$ Henning W Tiemeier, ${ }^{3}$ Reinier Timman, ${ }^{1}$ \\ Suzanne van de Vathorst ${ }^{8}$
}

To cite: Staphorst MS, Benninga MA, Bisschoff M, et al. The child's perspective on discomfort during medical research procedures: a descriptive study. BMJ Open 2017;7:e016077. doi:10.1136/ bmjopen-2017-016077

- Appendix A. Children's Discomfort during Research Procedures Questionnaire(CDRPQ); Appendix B. Discomfort - percentages per procedure

- Prepublication history and additional material are available. To view these files please visit the journal online (http://dx.doi. org/10.1136/bmjopen-2017016077).

Received 25 January 2017 Revised 23 May 2017 Accepted 29 June 2017

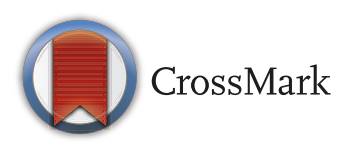

For numbered affiliations see end of article.

Correspondence to

Mira S Staphorst;

mstaphorst@gmail.com

\section{ABSTRACT}

Objective The evaluation of discomfort in paediatric research is scarcely evidence-based. In this study, we make a start in describing children's self-reported discomfort during common medical research procedures and compare this with discomfort during dental check-ups which can be considered as a reference level of a 'minimal discomfort' medical procedure. We exploratory study whether there are associations between age, anxiety-proneness, gender, medical condition, previous experiences and discomfort. We also describe children's suggestions for reducing discomfort. Design Cross-sectional descriptive study.

Setting Paediatric research at three academic hospitals. Patients 357 children with and without illnesses (8-18 years, mean $=10.6$ years) were enrolled: 307 from paediatric research studies and 50 from dental care.

Main outcome measures We measured various generic forms of discomfort (nervousness, annoyance, pain, fright, boredom, tiredness) due to six common research procedures: buccal swabs, MRI scans, pulmonary function tests, skin prick tests, ultrasound imaging and venepunctures.

Results Most children reported limited discomfort during the research procedures (means: 1-2.6 on a scale from 1 to 5). Compared with dental check-ups, buccal swab tests, skin prick tests and ultrasound imaging were less discomforting, while MRI scans, venepunctures and pulmonary function tests caused a similar degree of discomfort. $60.3 \%$ of the children suggested providing distraction by showing movies to reduce discomfort. The exploratory analyses suggested a positive association between anxiety-proneness and discomfort.

Conclusions The findings of this study support the acceptability of participation of children in the studied research procedures, which stimulates evidence-based research practice. Furthermore, the present study can be considered as a first step in providing benchmarks for discomfort of procedures in paediatric research.

\section{INTRODUCTION}

There is a need to improve treatments and licensed medication for children

\section{Strengths and limitations of this study}

- This is the first large-scale study on children's discomfort of research procedures. It can help to establish benchmarks for discomfort of research procedures in paediatric research.

- The findings of this study support the acceptability of participation of children in the studied research procedures, which stimulates evidence-based research practice

- We included a limited number of children for measuring discomfort, of which most were healthy 11 year olds. For generalisability, future research should include larger numbers and more heterogeneous groups of children.

- Although this study gives insight into the degree of discomfort, it needs to be established whether these degrees correspond with the concepts of 'minimal discomfort', a 'minor increase over minimal discomfort' or 'more than minimal discomfort' that institutional review boards use in their evaluation of research protocols.

- A limitation of this study is the cross-sectional design for comparing discomfort during research procedures and dental check-ups. A design with paired measurements from the same child might have given a more accurate reference level of discomfort.

by conducting paediatric research. ${ }^{1}$ For instance, it is estimated that $25 \%$ to $65 \%$ of all prescribed paediatric drugs are used off-label, ${ }^{2}$ which exposes children to an increased risk of medication underdose or overdose. Paediatric research, however, is complicated by the obligation to protect children against the risks and discomfort of research procedures. It is the responsibility of institutional review boards (IRBs) to estimate the risks and discomfort of research 
procedures and evaluate whether these are acceptable for the children. Primarily in case of discomfort, IRBs base this evaluation on their intuition and experiences, which may not necessarily give a representative view of children's experiences..$^{3-6}$ Consequently, this can lead to the rejection of studies when discomfort is expected to be excessive and vice versa. Preferably, the estimation of discomfort is based on group-level data of children's discomfort during research procedures, but unfortunately, these data are scarce. In this study, we therefore make a start in describing children's self-reported discomfort during research procedures. These data are an important first step in providing an empirical basis for the evaluation by IRBs and eventually providing benchmarks for the level of discomfort that might be expected for children with a given procedure.

We measured discomfort during research procedures instead of during a research study as a whole to make the results generalisable to children who undergo these procedures in future research, and because IRBs often evaluate the research procedures of a study separately. ${ }^{7-9}$ By addressing research procedures, this study provides a crucial complement to previous studies that have measured children's overall reactions to participation in research studies, such as the understanding of your rights of being a research participant. ${ }^{10-13}$ We compared the outcomes to discomfort of children during routine dental check-ups. In several countries, like the USA, IRBs have to establish whether discomfort of paediatric research activities is minimal in relation to children's 'daily life' activities or medical/psychological routine examinations that are regarded as minimal discomfort. Therefore, we compared discomfort in research to dental check-ups because regular dental check-ups are medical routine examinations that all children in our country encounter approximately two times in a year (note: dental check-ups for children $0-18$ years are covered by basic health insurance in the Netherlands). In this way, the dental check-ups could function as a 'reference level' of minimal discomfort. Furthermore, we exploratory studied whether there is an association between age, anxiety-proneness, gender, medical condition and previous experiences with the procedure, and children's discomfort. It is known that most of these factors are important for IRBs to consider when they estimate the discomfort of research procedures for the children. In addition, children were asked for suggestions to reduce discomfort.

\section{MATERIALS AND METHODS \\ Participants}

We used a convenience sample in which we aimed to include 50 children for each research procedure, or as much we could enrol within the time frame of our study. ${ }^{14}$ Due to the exploratory nature of our study and the absence of previous data using the Children's Discomfort during Research Procedures Questionnaire (CDRPQ), it was not possible to calculate a sample size needed for our study or to do a valid power analysis. The number of 50 children is an educated guess, based on the duration of our study and the availability of children undergoing the research procedure at the different locations during the inclusion period of our study.

Children were eligible to participate if they met the following criteria: (1) aged between 8-18 years, (2) fluent in Dutch, (3) no current psychological treatment for pain or anxiety disorders, (4) no psychosocial problems as diagnosed in the Diagnostic and Statistical Manual of Mental Disorders at the time of enrolment and (5) accompanied by a parent or caretaker. This information was determined by consultation of parent(s) or the child's medical record.

The children were recruited from research studies being conducted at three academic hospitals in the Netherlands. In addition, children without a known illness who had a check-up visit to the dentist were included. The same inclusion criteria were applied to this group. Children were enrolled between March 2014 and June 2015.

\section{Procedure}

First, the researchers conducting the research studies approached children and their parents if they were willing to participate in our study. Interested children and parents were provided with more information about the study by the first author or a research assistant. After agreement, written consent from parents and written child assent (>12 years) were obtained. Children younger than 12 gave oral assent to participate. Directly after the research procedure, the children completed two questionnaires on an iPad mini tablet to measure discomfort and anxiety-proneness. We asked the children directly after they underwent the medical procedure because we thought this would correspond to the 'highest' level of discomfort for the children. From other research areas (eg, pain research), we know that measures that are as close as possible to the event are considered to be more valid than delayed retrospective measures which bear the risk of recall bias. Parents provided demographic information. All children received a gift card $(€ 7.50)$ after completing the questionnaires.

\section{Instruments}

\section{Discomfort}

We developed the Children's Discomfort during Research Procedures Questionnaire (CDRPQ) because no appropriate instrument existed for the aim of the current study. ${ }^{15}$ Instruments that measure children's self-reported experiences in medical situations often focus on the measurement of pain, distress or anxiety. Discomfort-which is mentioned as an important assessment criterion for research participation in most ethics guidelines and regulations-also involves other aspects than pain, distress and anxiety, as was shown in an interview study we conducted about the face-validity of discomfort from the child's perspective. ${ }^{16}$ Measuring various forms of discomfort therefore provides a more thorough measure 
of the child's discomfort than only focusing on anxiety or pain. We aimed for an instrument that measures forms of discomfort that are applicable to all kinds of research procedures. Therefore, the CDRPQ can be considered as a generic questionnaire.

The CDRPQ contains: (1) six questions about generic types of discomfort (nervousness, annoyance, pain, fright, boredom and tiredness), which are measured using Likert scales ranging from $1=$ 'not discomforting' to $5=$ 'extremely discomforting' and (2) one open question about suggestions for reducing discomfort (see online supplementary appendix A. Note: the CDRPQ was developed in Dutch and then translated to English for this manuscript). Validity and test-retest reliability were acceptable. ${ }^{15}$

\section{Anxiety proneness}

Anxiety proneness was measured using the Dutch translation of the trait scale of the State-Trait Anxiety Inventory for Children (STAI-C) ${ }^{17}$ or the anxiety scale of the Child Behaviour Checklist (CBCL), ${ }^{18}$ depending on which questionnaire was already being used by the participating studies. Previous research shows that there are little differences in measuring anxiety by the trait scale of the STAI-C and the anxiety scale of the CBCL when parent reported, ${ }^{19}$ and that these scales are highly correlated $(r=0.77) .{ }^{20}$ The trait scale of the STAI-C is self-reported and addresses the frequency and intensity of anxiety symptoms in general. It consists of 20 items (eg, 'I worry about school). ${ }^{21}$ The STAI-C trait scale has shown good internal consistency (Cronbach's $\alpha>0.80$ ) and acceptable test-retest reliability $(r>0.65) .{ }^{17}$ The anxiety scale of the CBCL is parent-reported and includes six questions on anxiety problems (eg, 'fear of animals, situations or places'). The CBCL has shown good validity and reliability. ${ }^{18}$

\section{Demographics}

Parents provided information on demographics.

\section{Medical procedures}

\section{Research procedures}

We measured children's experiences during six research procedures: buccal swabs, MRI scans, pulmonary function tests, skin prick tests, ultrasound imaging and venepunctures (table 1). The research procedures were selected based on the following criteria: no general anaesthesia necessary, perceived by a consulted group of paediatric healthcare professionals as possibly causing discomfort, and performed in the participating hospitals during the time frame of our study. Almost all children underwent the research procedures for non-therapeutic research purposes; the pulmonary function tests and some venepunctures were performed as part of therapeutic research studies.

\section{Dentist}

We measured the experiences of a group of children without a known illness during regular check-up visits to a general academic dental centre (table 1). Fifth-year dentistry students performed supervised dental check-ups on children at this academic dental centre.

\section{Data analysis}

The data were analysed using SPSS version21.0. For each procedure, we calculated the means of the different forms of discomfort, the percentages of the different levels of discomfor, and an average discomfort score based on the six forms of discomfort. As most data were skewed, we used non-parametric statistics. A Kruskal-Wallis Test and Mann-Whitney U tests were used to explore differences between the procedures in the average discomfort score. We used Spearman correlations to explore the relation between the average discomfort score and age and anxiety-proneness. MannWhitney $\mathrm{U}$ tests were used to explore differences in the average discomfort score between children with and without an illness, boys and girls and children with and

Table 1 Description of the medical (research) procedures

\begin{tabular}{ll}
\hline Procedure & Description \\
\hline Buccal swab test & Taking mucosal epithelial cells from the inner cheek lining using a small brush. \\
MRI scan & MRI of different parts of the body, particularly of the head. The MRI scans lasted between 30 and \\
& 60 min and were performed without sedation. \\
Pulmonary function test & Regular pulmonary function test that lasted between 15 and 30 min. \\
Skin prick test & $\begin{array}{l}\text { Children were tested for } 20 \text { allergens. A droplet of each allergen was placed on the inner forearm and } \\
\text { penetrated through to the skin using a specially modified lancet. }\end{array}$ \\
Ultrasound imaging & $\begin{array}{l}\text { Ultrasound imaging used for research purposes was an echocardiogram. For clinical care purposes, } \\
\text { ultrasound imaging was particularly an echocardiography and in some cases ultrasounds were made } \\
\text { of the lymph nodes, the head or the abdomen. }\end{array}$ \\
Venepuncture & $\begin{array}{l}\text { One to three } 10 \mathrm{~mL} \text { tubes of blood were collected. In one of the two studies children could choose to } \\
\text { have EMLA-cream* applied before the venepuncture. None of the children had a local anaesthetic. } \\
\text { During the dental check-up a general check was carried out, dental plaque was removed and children } \\
\text { were given instructions on how to brush their teeth correctly. A new appointment was made for dental } \\
\text { caries or other abnormalities. }\end{array}$ \\
\hline
\end{tabular}

* EMLA cream is a local anesthetic. It works by blocking nerves from transmitting painful impulses to the brain. 
without previous experiences. Concerning the suggestions of the children to reduce discomfort, the first author coded the question 'What would you suggest to make (procedure $X$ ) less annoying?' into categories. A supervising researcher checked these categories (JH) and disagreements were discussed until consensus was reached.

\section{Ethical approval}

The IRB of the VU Medical Centre in Amsterdam (The Netherlands) indicated that there was no risk or discomfort associated with this study (ie, completing the questionnaires) and stated that it is exempt from requiring approval under Dutch Law (2014/010).

\section{RESULTS}

\section{Participants}

Four hundred and forty-three children were potentially suitable for participation in our study, of which 38 children $(8.8 \%)$ did not meet the inclusion criteria (24 in research and 14 from the dental clinic): two children did not speak Dutch fluently, five children were not accompanied by a parent and 31 children were too young or too old. Of the 396 children who were invited to participate, 357 children agreed to participate $(90.2 \%)$. The most frequently mentioned reason for declining was lack of time of the parents $(56 \%)$, followed by 'no interest' (26\%). Three hundred and seven children were enrolled from clinical research and 50 from an academic dental clinic. The majority of the children in research did not have a known illness $(82.7 \%)$; their mean age was 10.5 years. Further characteristics of the children are presented in table 2.

\section{Discomfort during research procedures (CDRPQ)}

Table 3 shows the means and SD of the discomfort children experienced. The percentages of children's reports on the different levels of discomfort can be found in online supplementary appendix B.

The percentages of children who did not experience discomfort varied from $21.9 \%$ to $100 \%$. Moreover, for three procedures (buccal swab, skin prick testing and ultrasound imaging), the percentage of children who reported 'no discomfort' was more than $50 \%$. For the children who did experience discomfort, the mean discomfort scores generally were low: most reported 'slight' discomfort or sometimes 'somewhat' discomfort. An exception is that $18 \%$ of the children undergoing an MRI scan experienced this as 'very' or 'extremely' tiring.

There were significant differences in discomfort between the procedures $(p<0.001)$. Compared with check-up visits to the dentist, discomfort of buccal swab tests, skin prick tests and ultrasound imaging were less discomforting $(\mathrm{p}=0.002-0.007)$, while MRI scans, venepunctures and pulmonary function tests caused a similar degree of discomfort $(\mathrm{p}=0.05-0.26)$.

\section{Suggestions to reduce discomfort}

A large group of the children in clinical research (62.6\%) suggested that distraction during the research procedures, preferably in the form of a movie, would reduce discomfort (table 4).

\section{Exploring potential relations between discomfort and demographic factors}

There was a significant correlation between anxiety-proneness, measured with the STAI-C $(\mathrm{p}=0.004)$, and discomfort. Anxiety-proneness, measured with the CBCL $(p=0.09)$, and discomfort showed a trend for a correlation. There was no significant correlation between age and discomfort $(\mathrm{p}=0.32)$. There were no significant differences in discomfort between healthy children and children with a chronic condition $(\mathrm{p}=0.78)$, boys and girls $(p=0.89)$ and children who had a previous experience or children who underwent the research procedure for the first time $(\mathrm{p}=0.31)$.

\section{DISCUSSION}

This is the first large-scale study investigating children's self-reported discomfort during research procedures. It is in line with the trend of actively involving children in expressing their experiences in medical and research situations. Our study shows that many children did not experience discomfort during the studied research procedures and the level of discomfort for the children who did experience discomfort is limited.

Although the studied research procedures may not be the most invasive ones, it is important to have actual data on the discomfort children experience during these research procedures rather than making assumptions. Besides, research shows that there are significant differences in the evaluation of discomfort of research procedures among IRB members, ${ }^{22}{ }^{23}$ which supports the importance of self-reported data by children during the evaluation of study protocols.

Looking at the different forms of discomfort, it is remarkable that the scores of the children on being bored and tired are higher than the scores on the other forms of discomfort. Although a boring or tiring research procedure may not be considered by IRBs as unacceptable in terms of discomfort, these are important forms of discomfort for children and can be a reason for them to refuse undergoing this procedure (in the future). For this reason, we believe it is important that these forms of discomfort are explicitly taken into account when evaluating discomfort by IRBs.

In several ethics codes and guidelines, minimising discomfort is a requirement for paediatric research. ${ }^{24} 25$ According to the majority of the children in our study, distraction can help to achieve this. Distraction is proven to be cost-effective in reducing discomfort during medical procedures in children of all ages. ${ }^{26-31}$ While children preferred to be distracted by movies, during some procedures it may be more feasible to distract children by providing music, toys or decoration on walls and ceilings.

\section{Strengths and limitations}

The outcomes of this study can help to establish benchmarks for the discomfort of research procedures in 


\begin{tabular}{|c|c|c|c|}
\hline Demographics & Research $(n=307)$ & Dentist $(n=50)$ & Total $(n=357)$ \\
\hline \multicolumn{4}{|l|}{ Gender (\%) } \\
\hline Boy & 158 (51.5\%) & 27 (54\%) & $185(51.8 \%)$ \\
\hline Girl & $149(48.5 \%)$ & $23(46 \%)$ & $172(48.2 \%)$ \\
\hline \multicolumn{4}{|l|}{ Age (\%) } \\
\hline Mean \pm SD & $10.5 \pm 1.8$ & $10.8 \pm 1.5$ & $10.6 \pm 1.7$ \\
\hline$<12$ years & $273(88.9 \%)$ & 38 (76\%) & 311 (87.1\%) \\
\hline$\geq 12$ years & $34(11.1 \%)$ & $12(24 \%)$ & $46(12.9 \%)$ \\
\hline \multicolumn{4}{|l|}{ Procedure (\%) } \\
\hline Buccal swab & 25 (8.1\%) & - & 25 (7.0\%) \\
\hline MRI & $89(29.0 \%)$ & - & $89(24.9 \%)$ \\
\hline Pulmonary function test & $9(2.9 \%)$ & - & $9(2.5 \%)$ \\
\hline Skin prick test & $75(24.4 \%)$ & - & $75(21.0 \%)$ \\
\hline Ultrasound imaging & $77(25.1 \%)$ & - & $77(21.6 \%)$ \\
\hline Venepuncture & $32(10.4 \%)$ & - & $32(9 \%)$ \\
\hline Check-up visit at dentist & - & $50(100 \%)$ & $50(14 \%)$ \\
\hline \multicolumn{4}{|l|}{ Medical condition (\%) } \\
\hline ADHD/ADD & $4(1.3 \%)$ & - & 4 (1.1\%) \\
\hline Cystic fibrosis & $6(2.0 \%)$ & - & $6(1.7 \%)$ \\
\hline Healthy (ie, no known illness) & $254(82.7 \%)$ & $50(100 \%)$ & $304(85.2 \%)$ \\
\hline Inflammatory bowel disease & $36(11.7 \%)$ & - & $36(10.1 \%)$ \\
\hline Oncological condition & $1(0.3 \%)$ & - & $1(0.3 \%)$ \\
\hline Primary ciliary dyskinesia & $4(1.3 \%)$ & - & $4(1.1 \%)$ \\
\hline Other condition & $2(0.7 \%)$ & - & $2(0.6 \%)$ \\
\hline Previous experience with procedure (\%) & $148(48.2 \%)$ & $50(100 \%)$ & $198(55.5 \%)$ \\
\hline Trait-anxiety-STAI-C & $\mathrm{n}=82$ & $n=36$ & $n=118$ \\
\hline Mean \pm SD & $29.3 \pm 5.7$ & $28.9 \pm 5.7$ & $29.2 \pm 5.9$ \\
\hline Range & $20-44$ & $22-42$ & $20-44$ \\
\hline Trait-anxiety-CBCL & $\mathrm{n}=192$ & $\mathrm{n}=0$ & $n=192$ \\
\hline Mean \pm SD & $1.0 \pm 1.4$ & - & $1.0 \pm 1.4$ \\
\hline Range & $0-6$ & - & $0-6$ \\
\hline
\end{tabular}

CBCL, Child Behaviour Check List; STAI-C, State-Trait Anxiety Inventory for Children.

children, and thereby assist IRBs, paediatric researchers, parents and children in their estimation of the acceptability of these procedures for research participation. Other strengths of the study are the multisite enrolment for generalisability, the large number of children in some of the procedures, the (exploratory) comparison with a routine medical procedure that is regarded as causing minimal discomfort, the use of a specifically developed questionnaire to measure different forms of discomfort (CDRPQ), and the suggestions for reducing discomfort.

As we were dependent on the participating studies, we were unable to include the intended number of children for some procedures, because fewer children took part in these studies than expected or were included at a later stage than initially planned. This has reduced the power of the outcomes of some research procedures (eg, pulmonary function tests). On the other hand, for some procedures more children were included than initially planned (eg, MRI scans).

We used different groups of children to compare discomfort in clinical research with dental check-ups. A design with paired measurements from the same child might have given a more accurate reference level of discomfort.

For this study, we aimed to include both healthy and ill children. However, the majority of the participants in our research appeared to be healthy. Therefore the results might not be representative for ill children. However, the explorative analysis to investigate differences in discomfort between healthy and ill children did not show any differences in discomfort. 


\begin{tabular}{lcc}
\hline Table 4 Suggestions to reduce discomforts & \\
\hline Suggestion & $\begin{array}{l}\text { Number of } \\
\text { children }\end{array}$ & Percentage \\
\hline Distraction - Movie & 185 & 60.3 \\
Distraction - Music & 1 & 0.3 \\
Distraction - Small talk & 2 & 0.7 \\
Distraction - other forms & 4 & 1.3 \\
Less noise (MRI) & 24 & 7.8 \\
Fewer physical sensations & 11 & 3.6 \\
Warm gel (echoscope) & 4 & 1.3 \\
Warmer room temperature (MRI) & 3 & 1 \\
Shorter duration & 1 & 0.3 \\
Receiving present & 1 & 0.3 \\
Other & 11 & 3.6 \\
No suggestion & 60 & 19.5 \\
Total & $307^{\star}$ & 100 \\
\hline
\end{tabular}

${ }^{*}$ Only children in clinical research.

Furthermore, the degree of discomfort may be relative to the presence of other research procedures the children underwent in the studies. As there was little variation in their ratings of discomfort, we assume that the other research procedures did not have much influence on children's reports.

All children included in our study assented to undergo the research procedures, which is why our study might be hampered by a selection bias (note: this is applicable to all studies investigating children's experiences in paediatric research). It may be possible that highly anxious children declined to undergo the research procedures because of expected discomfort or anxiousness, or that they may not have been approached to participate for this reason (ie, gatekeeping by the researcher/paediatrician). ${ }^{32}$ The fact that we did not have to exclude children with anxiety-disorders (ie, one of the exclusion criteria) nor that children did have high scores on the anxiety-proneness measures, supports this.

Implications and recommendations for those involved in paediatric research

Institutional review boards

We encourage IRBs to use self-reported data of the children when evaluating discomfort for reasons mentioned above. To be able to use children's self-reported information on discomfort of all kinds of research procedures and across children from all kinds of backgrounds, it is needed that these data are collected and disseminated. IRBs can play a key role in this by requiring these data as part of a study protocol and recommending paediatric researchers to register children's experiences.

Paediatric researchers

We recommend that paediatric researchers routinely include a brief assessment of the impact of the research procedures of their studies by asking the participating 
children, for example, the CDRPQ, which we developed for this purpose. To avoid overloading paediatric researchers with extra work and responsibilities during a study visit, it would be ideal if children can report their experiences directly on a website/app. As such, paediatric researchers can limit their tasks to emphasising the opportunity and importance of reporting these experiences to children (and their parents) and to refer them to the website/app concerned. Of course, this website/ app need to be developed first.

During the informed consent procedure, we encourage researchers providing parents and children with information on expected discomfort of research procedures based on empirical data, in order to facilitate their decision-making for participation.

It is important that discomfort in paediatric research is reduced as much as possible. This can be achieved by standard asking children for their suggestions to reduce discomfort, and-if feasible-to apply these in their studies. As we showed in this study, many children suggested providing (more) distraction, for instance, by showing short movies.

\section{Children and parents}

For children (and parents) who are approached for research participation, it can be helpful when they have access to information on discomfort of research procedures of children in previous research. It provides them with additional information on what to expect from undergoing research procedures from the perspective of their peers. This information can facilitate decision-making for research participation, as they will be better informed. For instance, if the majority of children do not experience a specific research procedure as discomforting, it may be a reason for others to agree with undergoing this procedure too.

The availability of children's self-reported data on discomfort is dependent on the willingness of children to report on their experiences during research participation. As we learnt from this study, most children are willing to report these experiences as long as it does not require much extra time.

\section{Future research}

For generalisability, future research should include larger numbers and more heterogeneous groups of children, in particular during pulmonary function tests. Future research is also needed to describe children's discomfort during other (more invasive) research procedures. We therefore recommend paediatric researchers to include measures in their studies (eg, CDRPQ) to investigate discomfort related to the research procedures involved, and also disseminate these results (note: since March 2017 in the Netherlands an addition to the law on research participation was implemented which requires to define and monitor discomfort in paediatric research (http://www.ccmo.nl/nl/verruiming-mogelijkhedenmedisch-wetenschappelijk-onderzoek-met-minderjarigeen-wilsonbekwame-proefp).
For IRBs and paediatric researchers who evaluate the level of discomfort of (non-therapeutic) research procedures, it is important to know which research procedures involve minimal, a minor increase over minimal discomfort or more than minimal discomfort. Unfortunately, there are no clear guidelines for this. Future researchin which IRBs, paediatric researchers, children and their parents are consulted-is therefore needed to determine cut-off levels for this.

\section{CONCLUSION}

Our findings support the acceptability of participation of children in the studied procedures for research purposes because children experienced limited discomfort. The results are an important first step in providing benchmarks for discomfort of research procedures in paediatric research, and contribute to the evidence-based evaluation of discomfort in research.

\section{Author affiliations}

${ }^{1}$ Department of Psychiatry, Section Medical Psychology and Psychotherapy, Erasmus University Medical Centre, Rotterdam, The Netherlands

${ }^{2}$ Department of Paediatrics, Emma Children's Hospital, Academic Medical Center (AMC), Amsterdam, The Netherlands

${ }^{3}$ Departments of Paediatrics and Child Psychiatry, Sophia Children's Hospital, Erasmus University Medical Centre, Rotterdam, The Netherlands

${ }^{4}$ Department of Paediatrics, VU University Medical Center (VUmc), Amsterdam, The Netherlands

${ }^{5}$ Department of Pedodontology, Academic Center Dentistry Amsterdam (ACTA), Amsterdam, The Netherlands

${ }^{6}$ Section of Clinical Neuropsychology, VU University, Amsterdam, The Netherlands ${ }^{7}$ Department of Clinical Psychology/EMGO+, VU University, Amsterdam, The Netherlands

${ }^{8}$ Department of Ethics and Philosophy, Erasmus University Medical Centre, Rotterdam, The Netherlands

Contributors MS acted on behalf of the BURDEN-group. All remaining authors are the BURDEN-group. MS conceptualised and designed this study, carried out the data collection, drafted the initial manuscript and approved the final manuscript as submitted. JH, JP and JBG conceptualised and designed this study, supervised the study, reviewed and revised the manuscript and approved the final manuscript as submitted. RT assisted with the statistical analyses of the data, reviewed and revised the manuscript, and approved the final manuscript as submitted. SV and JVB conceptualised and designed this study, reviewed and revised the manuscript and approved the final manuscript as submitted. MAB, MB, IB, KD, EH, VJ, KJ, JJ, AK, MK, JO, MP, LR, LdR, GHT, HT assisted with acquisition of data, reviewed and revised the manuscript and approved the final manuscript as submitted.

Funding This work was supported by ZonMw (The Netherlands Organization for Health Research and Development), grant number 113203202.

Competing interests None declared.

Patient consent Detail has been removed from this case description/these case descriptions to ensure anonymity. The editors and reviewers have seen the detailed information available and are satisfied that the information backs up the case the authors are making.

Provenance and peer review Not commissioned; externally peer reviewed.

Data sharing statement The dataset is available by contacting the corresponding author.

Open Access This is an Open Access article distributed in accordance with the Creative Commons Attribution Non Commercial (CC BY-NC 4.0) license, which permits others to distribute, remix, adapt, build upon this work non-commercially, and license their derivative works on different terms, provided the original work is properly cited and the use is non-commercial. See: http://creativecommons.org/ licenses/by-nc/4.0/ 
(c) Article author(s) (or their employer(s) unless otherwise stated in the text of the article) 2017. All rights reserved. No commercial use is permitted unless otherwise expressly granted.

\section{REFERENCES}

1. Kaplan W, Wirtz V, Mantel-Teeuwisse A, et al. Priority Medicines for Europe and the World 2013 Update. Geneva: World Health Organization in collaboration with Utrecht University and Boston University, 2013.

2. Kimland $\mathrm{E}$, Odlind V. Off-label drug use in pediatric patients. Clin Pharmacol Ther 2012;91:796-801.

3. Chambers CT, Giesbrecht K, Craig KD, et al. A comparison of faces scales for the measurement of pediatric pain: children's and parents ratings. Pain 1999;83:25-35.

4. McCarthy AM, Kleiber C, Hanrahan K, et al. Factors explaining children's responses to intravenous needle insertions. Nurs Res 2010;59:407-16.

5. Rid A, Emanuel EJ, Wendler D. Evaluating the risks of clinical research. JAMA 2010;304:1472-9.

6. Rømsing J, Møller-Sonnergaard J, Hertel S, et al. Postoperative pain in children: comparison between ratings of children and nurses. $J$ Pain Symptom Manage 1996;11:42-6.

7. Weijer $\mathrm{C}$. The ethical analysis of risk in intensive care unit research. Crit Care 2004;8:85-6.

8. McRae A, Weijer C. U.S. Federal Regulations for emergency research: a practical guide and commentary. Acad Emerg Med 2008;15:88-97.

9. Weijer $\mathrm{C}$. The ethical analysis of risk. J Law Med Ethics 2000;28:344-61.

10. Kassam-Adams N, Newman E. The reactions to research participation questionnaires for children and for parents (RRPQ-C and RRPQ-P). Gen Hosp Psychiatry 2002;24:336-42.

11. Kassam-Adams N, Newman E. Child and parent reactions to participation in clinical research. Gen Hosp Psychiatry 2005;27:29-35.

12. Barakat LP, Patterson CA, Mondestin V, et al. Initial development of a questionnaire evaluating perceived benefits and barriers to pediatric clinical trials participation. Contemp Clin Trials 2013;34:218-26.

13. Chu AT, Deprince AP, Weinzierl KM. Children's perception of research participation: examining trauma exposure and distress. J Empir Res Hum Res Ethics 2008;3:49-58.

14. Staphorst MS, Hunfeld JA, Timman R, et al. Hearing the voices of children: self-reported information on children's experiences during research procedures: a study protocol. BMJ Open 2015;5:e009053. Epub ahead of print.

15. Staphorst MS, Timman R, Passchier J, et al. The development of the 'Children's Discomfort During Research Procedures Questionnaire' (CDRPQ). Manuscript submitted for publication 2016.
16. Staphorst MS, Hunfeld JA, van de Vathorst S, et al. Children's self reported discomforts as participants in clinical research. Soc Sci Med 2015;142:154-62.

17. Bakker F, Wieringen PWC, PloegHM, et al. Handleiding bij de ZelfBeoordelings Vragenlijstvoor Kinderen, ZBV-K [Manual for the SelfEvaluation Questionnaire for Children,STAIC]. Lisse, the Netherlands: Swets \& Zeitlinger, 1989

18 Verhulst F, Van der Ende J, Koot H. Manual for the Child Behavior Checklist (in Dutch). Rotterdam: Department of Child and Adolescent Psychiatry, Erasmus Medical Centre/Sophia, 1996.

19 Seligman LD, Ollendick TH, Langley AK, et al. The utility of measures of child and adolescent anxiety: a meta-analytic review of the revised Children's Manifest Anxiety Scale, the State-Trait Anxiety Inventory for Children, and the Child Behavior Checklist. J Clin Child Adolesc Psychol 2004;33:557-65.

20 Kendall PC, Puliafico AC, Barmish AJ, et al. Assessing anxiety with the child behavior checklist and the teacher report form. J Anxiety Disord 2007;21:1004-15.

21 Spielberger C. Manual for the state-trait anxiety inventory for children. Palo Alto, California, USA: Consulting Psychologists Press, 1973.

22. Shah $\mathrm{S}$, Whittle A, Wilfond B, et al. How do institutional review boards apply the federal risk and benefit standards for pediatric research? JAMA 2004;291:476-82.

23. Janofsky J, Starfield B. Assessment of risk in research on children. $J$ Pediatr 1981;98:842-6.

24. US Department of Health and Human Services. Code of Federal Regulations. Protection of human subjects (45 CFR 46). 102 (i). Revised 2009.

25. European Parliament. Directive 2001/20/EC. Clinical Trials Directive. Luxembourg: Office for Official Publications of the European Communities, 2001.

26. Alvarez C, Fernández Marcos A. Psychological treatment of evoked pain and anxiety by invasive medical procedures in paediatric oncology. Psychology in Spain 1997;1:17-36.

27. Uman LS, Birnie KA, Noel M, et al. Psychological interventions for needle-related procedural pain and distress in children and adolescents. Cochrane Database Syst Rev 2013:CD005179.

28. Broome ME, Rehwaldt M, Fogg L. Relationships between cognitive behavioral techniques, temperament, observed distress, and pain reports in children and adolescents during lumbar puncture. J Pediatr Nurs 1998;13:48-54

29. Dahlquist LM, Busby SM, Slifer KJ, et al. Distraction for children of different ages who undergo repeated needle sticks. J Pediatr Oncol Nurs 2002;19:22-34.

30. Nguyen TN, Nilsson S, Hellström AL, et al. Music therapy to reduce pain and anxiety in children with cancer undergoing lumbar puncture: a randomized clinical trial. J Pediatr Oncol Nurs 2010;27:146-55.

31. DeMore M, Cohen LL. Distraction for Pediatric immunization pain: a critical review. J Clin Psychol Med Settings 2005;12:281-91.

32. Tromp K, Vathorst S. Gatekeeping by professionals in recruitment of pediatric research participants: indeed an undesirable practice. Am J Bioeth 2015;15:30-2. 